\title{
An Experimental Research on Bone Drilling Temperature in Orthopaedic Surgery
}

\author{
Yali Hou, Changhe Li ${ }^{*}$, Hongliang Ma, Yanbin Zhang, Min Yang and Xiaowei Zhang
}

School of Mechanical Engineering, Qingdao Technological University, 266033 Qingdao, China

\begin{abstract}
The bone drilling temperature fields under different cutting parameters and cooling modes were experimental researched by using common twist drill, diamond punching pin, diamond bullet-like grinding head and diamond spherical grinding head. Three cooling modes were applied, namely, natural air cooling, normal saline pouring cooling and normal saline spray cooling. K-thermocouple was used to measure temperature in bone hole. Results showed that the drill shape could influence drilling temperature greatly. The maximum drilling temperature of diamond spherical grinding head is $46.31^{\circ} \mathrm{C}$. The maximum drilling temperature of common twist drill is $42.1^{\circ} \mathrm{C}$ and that of diamond bullet-like grinding head is $38.29^{\circ} \mathrm{C}$. The drilling temperatures at drill speed is under $560 \mathrm{r} / \mathrm{min}, 900 \mathrm{r} / \mathrm{min}, 1,250 \mathrm{r} / \mathrm{min}$ and 2,100 r/min are $38.84^{\circ} \mathrm{C}, 41.1^{\circ} \mathrm{C}, 43.84^{\circ} \mathrm{C}$ and $46.31^{\circ} \mathrm{C}$. This reflects that under same of other drilling parameters, drilling temperature increases with the increase of drill speed. The maximum bone drilling temperatures of diamond punch pin under 2,100 $\mathrm{r} / \mathrm{min}$ speed of mainshaft and air cooling conditions vary as feed speed increase firstly and then decrease. The normal saline spray cooling has the lowest maximum drilling temperature of $\left(29.34^{\circ} \mathrm{C}\right)$ at same depth, following by normal saline pouring cooling of $\left(32.45^{\circ} \mathrm{C}\right)$ and air cooling of $\left(40.28^{\circ} \mathrm{C}\right)$ successively. The normal saline spray cooling has the best cooling effect, followed by normal saline pouring cooling and air cooling successively.
\end{abstract}

Keywords: Bone drilling, cooling mode, cutting parameters, orthopaedic surgery, temperature field.

\section{INTRODUCTION}

Bone fracture exists throughout the human history. People's understanding and therapy of bone fracture is developing continuously. There's written record in western countries that mixture of earth and gum as well as mixture of egg white and flour was used for fixing a fracture. The popular fracture treatment with gypsum and bandage was invented by European. This treatment is known as today's closed reduction and external fixation [1]. Closed reduction and external fixation is to restore broken bones firstly by tact or continuous traction, followed by external fixation with gypsum and bandage. The external fixation must cover adjacent joints to the bone fracture. Such treatment avoids open reduction and thereby protects fracture hematoma and periosteum, beneficial for fracture healing. However, although it heals fracture quicker than open reduction. Its long-time external fixation will cause anchylosis and muscular atrophy which take a long time for physiotherapy and exercise to recover functions. Elders are even difficult to recover completely.

Nowadays, serious bone fracture prefers open reduction and internal fixation to external fixation. Open reduction and internal fixation cuts soft tissue to expose bone fracture directly or only cut the position for internal fixation rather than the bone fracture. After reduction of fracture, metal

*Address correspondence to this author at the School of Mechanical Engineering, Qingdao Technological University, 266033 Qingdao, China; Tel: +86-532-85071757; Fax: +86-532-85071286;

E-mail: sy_lichanghe@163.com bone fracture plate, fastening screw, intramedullary nail, steel wire or biological synthetic materials which are highly compatible with body are used as internal fixation of the fracture. Although internal fixation ensures high-precision reduction of fracture and shortens postoperative recovery significantly. It has many potential adverse factors, because it attaches high attention on reduction and fixation during surgery and adopts much external interventions, but neglects living tissue of bones. It destroys fracture hematoma, hurts periosteum and surrounding of soft tissue, as well as weakens or even cuts off local blood supply, thus resulting in delayed fracture healing [2]. Though modern metal internal fixations have good biocompatibility with human bodies, this is not absolutely right. Additionally, internal factors of design or materials could affect physical properties of internal fixation materials, making them bent or broken. This will cause fracture displacement and malunion. Open reduction increases possibility of infection and operative complications. Once infection occurred, the internal fixation materials become foreign matters that are difficult to be compatible with human bodies. For tightening fixation, internal fixation materials are often fixed tightly on backbones or in marrow cavity. Since bone reacts to local pressure by bone absorption, internal fixation materials will not be intact and will not fix the fracture after a certain time. During orthopedic surgery, it is necessary to drill holes on fracture for screws to fix bone fracture plate and intramedullary nails. However, drilling is easy to generate over high temperature at the hole, which will kill bone cells. This will prolong recovery of patients or even operation failure. 
Due to the obvious superiority to existing fracture treatments, open reduction is applied more and more in clinical operation. However, it is not perfect and will also cause new problems. Accurate fracture reduction of bone surgery is attributed to internal fixation of metal bone fracture plate and intramedullary nails with screws. Such extruding fixation has high requirements on stability and safety of fixing threads [3]. As a result, failure of fixing threads will cause final failure of the operation. Investigations reported $2.1 \% \sim 7.1 \%[4,5]$ focile operation failure caused by failure of fixing threads. One important cause to failure of fixing threads is that over high bone drilling temperature kills bone cells and brings irreversible changes to bone structure and physical properties, thus increasing bone absorption surrounding screws that are fixed inside bones. Annular osteonecrosis caused by high temperature has been observed under X-ray. It also discovered thermal necrosis of bone cells when living bone cells stay under $47^{\circ} \mathrm{C}$ for $1 \mathrm{~min}$ [6].

Orthopedic drill is one of important instruments in orthopedic surgery. It is mainly used for drilling blind hole or through-hole at drumhead, skull, dentale and common human bones [7]. In practical orthopedic bone hole drilling, the surgeon must apply an appropriate axial force to ensure the hole drilling stable and smooth. However, bone drilling is different from metal cutting. Bone, a kind of unique multiorg composite, is composed of organics and inorganics. It will suffer very complicated deformation and forces during drilling. Moreover, considering severe conditions in practical surgery, orthopedic drill shall be designed and manufactured with sharp cutting edge, adequate stiffness and toughness, as well as high processing precision. In particular, it shall be excellent heat dissipation to control drilling temperature below $47^{\circ} \mathrm{C}$. This not only will improve the drilling quality and fixation effect of implantation materials, but also will shorten the recovery time of patient significantly.

Abundant exploratory researches on bone drilling temperature during orthopedic surgery have been reported. They mainly involve the following three aspects. Some focused on influence law of drilling parameters (e.g. speed of mainshaft, load and axial pressure) on bone drilling temperature. Subsequently, they chose optimized drilling parameters to control drilling temperature reasonably. Since it is difficult to use uniform variables in experiments, including experimental facility, temperature measuring equipment and bone materials, none agreed influence law of drilling parameters on bone drilling temperature have been reached yet. Some scholars tried to design new orthopedic drills to overcome strong drilling force, difficult drillings removal and over high temperature of traditional medical drills. Although some new orthopedic drills lower bone drilling temperature to a certain extent, they still used material cutting mechanism of continuous cutting edge and failed to control the drilling temperature strictly within the critical value of human bodies $\left(<47^{\circ} \mathrm{C}\right)$. They didn't solve the problem fundamentally. Some other scholars advocated to rinsing the bone with normal saline to lower bone drilling temperature. Although it is widely used in practical surgery, it is difficult for cooling liquid to reach to the drilling zone, restricting the cooling effect of normal saline greatly.
Many scholars studied critical temperature of osteonecrosis during orthopedic surgery. Augustin and Davila et al. [8] made a bone drilling experiment. They used thigh bone of $8 \sim 10$-month-old pig with $4 \sim 5 \mathrm{~mm}$ thick compact bone substance as testing material. Thermocouple with a measuring range of $-40 \sim 1200^{\circ} \mathrm{C}$ was used as the temperature measurer. The response time was less than $0.1 \mathrm{~s}$. ALG-100 drill which has several optional rotate speeds and feed rates were used. All applied testing equipments were checked and calibrated before the experiment. Firstly, a small hole was drilled and the thermocouple was bonded at 3 $\mathrm{mm}$ depth of the hole. Every hole was located by a guiding device. The distance between drilling hole and the hole with thermocouple was kept at $0.5 \mathrm{~mm}$. Three drills with different diameters $(2.5 \mathrm{~mm}, 3.2 \mathrm{~mm}$ and $4.5 \mathrm{~mm})$ were used. The experiment was implemented in laboratory under $84 \mathrm{~mm} / \mathrm{min}$ feed rate and $188 \mathrm{r} / \mathrm{min}, 462 \mathrm{r} / \mathrm{min}, 1140 \mathrm{r} / \mathrm{min}$ and 1820 $\mathrm{r} / \mathrm{min}$ speed of mainshaft. Temperature was kept $26^{\circ} \mathrm{C}$ throughout the whole experiment. According to the test data, bone drilling temperature increases with the acceleration of mainshaft.

Rafel [9] carried out an experimental study on high rotate speed and bone drilling temperature, but got conflicting results. He used a series of medical drills with different shapes to drill holes on upper jaw bone of human bodies without external pouring cooling. The final results showed that from $10,000 \mathrm{r} / \mathrm{min} \sim 350,000 \mathrm{r} / \mathrm{min}$, the maximum temperature is at $10,000 \mathrm{r} / \mathrm{min}$. This reflects that bone drilling temperature decreases with the acceleration of mainshaft.

To analyze effect of drilling speed on bone drilling temperature, Yang and Wang et al. [10] implemented drilling experiment on fresh fig tibia with different medical drills. The final experimental result reveals a proportional relationship between drilling speed and drilling temperature.

In the bone drilling experiment, Udiljak and Ciglar et al. [11] explored the influence law of cutting feed on drilling temperature by using a $4.5 \mathrm{~mm}$ drill. The cutting feeds were $0.02 \mathrm{~mm} / \mathrm{s}, 0.06 \mathrm{~mm} / \mathrm{s}$ and $0.1 \mathrm{~mm} / \mathrm{s}$, and the cutting speeds were set as $6 \mathrm{~m} / \mathrm{min}, 8 \mathrm{~m} / \mathrm{min}, 10 \mathrm{~m} / \mathrm{min}, 12 \mathrm{~m} / \mathrm{min}, 14$ $\mathrm{m} / \mathrm{min}$ and $16 \mathrm{~m} / \mathrm{min}$. Final result showed that bone drilling temperature decrease with the increase of cutting feed.

Larry and Matthews et al. [12] made a series of experiments on human femoral shaft. They paid attentions to effect of axial force on bone drilling temperature. They used four $0.25 \mathrm{~mm} \mathrm{NiCr-NiAl} \mathrm{shielded} \mathrm{thermocouples} \mathrm{to} \mathrm{measure}$ drilling temperature. The Wire of thermocouple was connected with four amplifiers and its signal was recorded by the galvanometer for recording ultraviolet ray. The response time for thermocouple reached $100^{\circ} \mathrm{C}$ was smaller than $6 \mathrm{~ms}$. To measure drilling axial force, the sample support was suspended on a steel cantilever with an electronic gauge. Output signals were recorded by the galvanometer for recording ultraviolet ray after being amplified. In the experiment, location of thermocouple and drilling holes were controlled by guide pad. The distances from thermocouple to drilling holes were $0.5 \mathrm{~mm}, 1.0 \mathrm{~mm}$, $2.0 \mathrm{~mm}$ and $3.0 \mathrm{~mm}$, respectively. Before the experiment, Ringer's solution flows cyclically in the marrow cavity, which is to maintain sample temperature at about $37^{\circ} \mathrm{C}$. The speed of mainshaft was $2900 \mathrm{r} / \mathrm{min}$ and the drill diameter 
was $3.2 \mathrm{~mm}$. Experimental data demonstrated that bone drilling temperature decreases with the increase of axial force.

Vaughn and Peyton [13] drilled holes on dentine under axial load range of $1 \sim 2$ pounds ( 1 pound $\approx 0.4536 \mathrm{~kg}$ ). The final test data showed that with the increase of axial force, bone drilling temperature rises. This disagrees with the results of Matthews and Hirsch.

Sorenson [14] drilled dentine without pouring cooling liquid. He concluded that within $0.3 \sim 0.5 \mathrm{~N}$ of axial force, drilling temperature shows an inverse "V-shaped" variation law.

Drilling temperature rise in orthopedic surgery is the collaborative consequence of many influencing factors. Scholars [15] have reported abundant experimental researches and theoretical explorations, and achieved some fruitful results. Influence law of cutting parameters, geometrical structure of drills and cooling mode on bone drilling temperature field is the key research problem. Based on simulation of drilling temperature of common twist drill and four new medical drills, it is discovered that structural shape of drills has an important impact on drilling temperature [16-23]. Brazed step drill and brazed twist drill could lower drilling temperature significantly [24-32]. However, no agreement on the influence law of cutting parameters on bone drilling temperature has been reached yet. Further associated research is needed. Furthermore, most previous researches are based on experimental exploration [33-45]. They involve more variables, but lack of corresponding theoretical supports. In this paper, bone drilling temperature fields under different cutting parameters and cooling modes were simulated by using brazed step drill and brazed twist drill to discuss influence law of cutting parameters and cooling modes. This lays foundations for reasonable optimization and selection of drilling parameters.

\section{PROCESSING CHARACTERISTICS OF BONE MATERIALS}

As a special connective tissue with good toughness and stiffness, human bones are characteristic of anisotropism. Bone contains porous calcification materials. There are abundant bone salts in intercellular substances. Bone salts are mainly composed of $84 \%$ calcium phosphate, $10 \%$ calcium carbonate, $2 \%$ calcium citrate and $2 \%$ disodium hydrogen phosphate. They distribute in organic matters of bones as amorphous calcium phosphate and hydroxyapatite crystals. Organic matters of bones mainly consist of collagen fiber, accounting for $95 \%$ of organic intercellular substances of bone tissue [15].

The Macrostructure of an adult thighbone is shown in Fig. (1). Two distinct structural tissues could be seen by separating the thighbone vertically. The hard and compact bone tissue on surface is called as compact bone. Many irregular rod-shaped or lamellar bone tissues at center and of two ends are called as bone trabecula. They interconnect into sponge and are also called as cancellous bone. Cancellous bone cavities connect with each other and are filled with hemopoietic tissues and blood vessels, known as bone marrow. Compact bone is a kind of compact material with about a specific gravity of 2 . Its external surface is covered by a layer of periosteum and its internal surface is covered by endosteum. Cancellous bone is formed by irregular parallel arrangements of several layers of bone lamella. They interconnect into a grid structure with uneven mesh sizes. It is visible that meshes are filled with bone marrow, blood vessels and nervous systems, which provide nutrition and oxygen for growth and repair of periosteum and endosteum. Therefore, meshes of cancellous bone are actually marrow cavities.

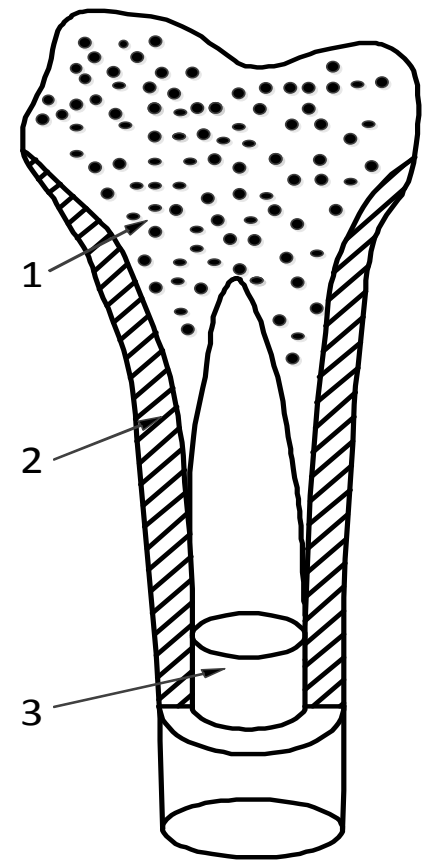

1-cancellous bone 2 - compact bone 3-bone marrow

Fig. (1). Macrostructure of adult thighbone.

Human bones are composed of organics and inorganics. Proportions of organic and inorganic in human bones vary at different growth stages. Hence, bones of different ages have different physical properties. Scholars have been interested in studying mechanical properties of healthy adult human bones and achieved satisfying results. Mean mechanical, thermal and physical properties of adult human bones and pig bones are listed in Table $\mathbf{1}[16,17]$.

Although bone materials have different components and metals. Bone deformation during cutting can be divided into three stages, namely, elastic deformation stage, plastic deformation stage and fracture stage. Influenced by load gradually, bone firstly show elastic deformation which shift to plastic deformation after stress reaches the yield stress. As stress continues to increase to the limit, bone materials get damaged and finally break [18].

In practical clinical orthopedic surgery, different positions of bone fracture may adopt different treatments, but the basic steps are similar. During surgery preparation, patients have to get X-ray to determine location and degree of bone fracture. Next, local anesthesia or general anesthesia will be implemented. During the surgery, the surgeon will choose an appropriate position to cut the fracture position and then uses a periosteal detacher to peel off the periosteum for drilling holes. Subsequently, the surgeon drills hole with an electronic drill and controls the drilling by his / her 
Table 1. The properties of material.

\begin{tabular}{|c|c|c|c|c|}
\hline Materials & Density $\left(\mathbf{k g} / \mathbf{m}^{\mathbf{3}}\right)$ & Shearing Strength $(\mathbf{M p a})$ & Specific Heat $(\mathbf{J} / \mathbf{K g} \cdot \mathbf{K})$ & Coefficient of Heat Conduction $(\mathbf{W} / \mathbf{m} \cdot \mathbf{k})$ \\
\hline \hline human bone & 2200 & 82 & 1150 & 2.2 \\
\hline pig bone & 2010 & 75 & 1330 & 1.7 \\
\hline
\end{tabular}

feeding force. This brings great risks to drilling. To prevent drilling out, researchers are committed to develop an autostop medical electric drill. After finishing the drilling, tightening screws and bone fracture plate is used to fix the bone fracture (Fig. 2), followed by wound closure and postoperative recovery $[18,19]$.

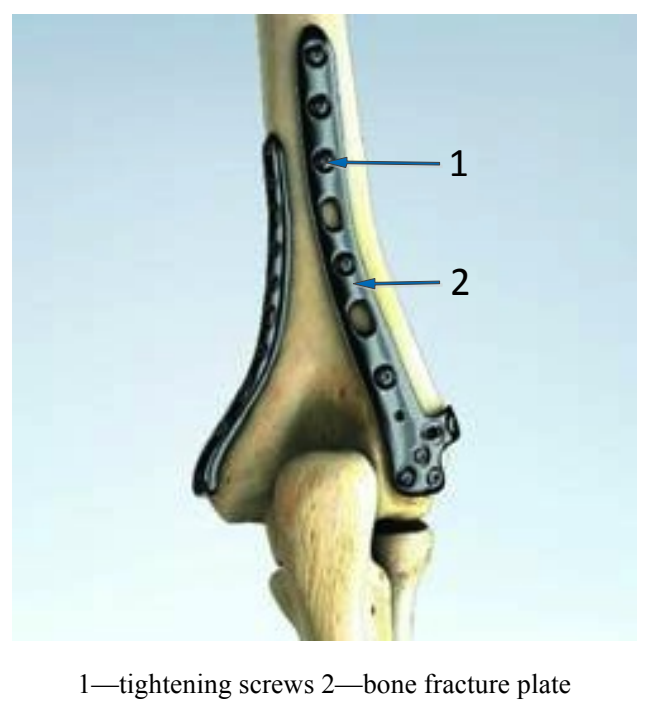

Fig. (2). Schematic diagram of fractures fixed.

Bone drilling quality determines postoperative recovery of patients. In the past, surgery usually used electric hand drill and one-time continuous drilling way which requires the surgeon who has rich clinical experience. Moreover, it is difficult to locate the holes accurately during the drilling process. Currently, surgeons often employ twice drilling way: pre-drilling and secondary reaming. The pre-drilling improves location accuracy of holes greatly and limits temperature rise of bone tissue to a certain extent. Meanwhile, the secondary reaming provides an accurate location reference point, preventing slipping and malposition during bone drilling effectively.

\section{EXPERIMENT DETAILS}

\subsection{Experimental Equipment}

The experiment used LT-13 bench drilling machine (Fig. 3). Main technical parameters include: four spindle speeds optional: $560 \mathrm{r} / \mathrm{min}, 900 \mathrm{r} / \mathrm{min}, 1,250 \mathrm{r} / \mathrm{min}$ and 2,100 r/min; maximum drill diameter: $13 \mathrm{~mm}$; table travel: $360 \mathrm{~nm}$; travel of spindle: $85 \mathrm{~mm}$; motor power: $0.37 \mathrm{kw}$.

Three cooling modes were applied, namely, natural air cooling, normal saline pouring cooling and normal saline spray cooling. The normal saline pouring cooling was realized by the pouring cooling liquid supply system in

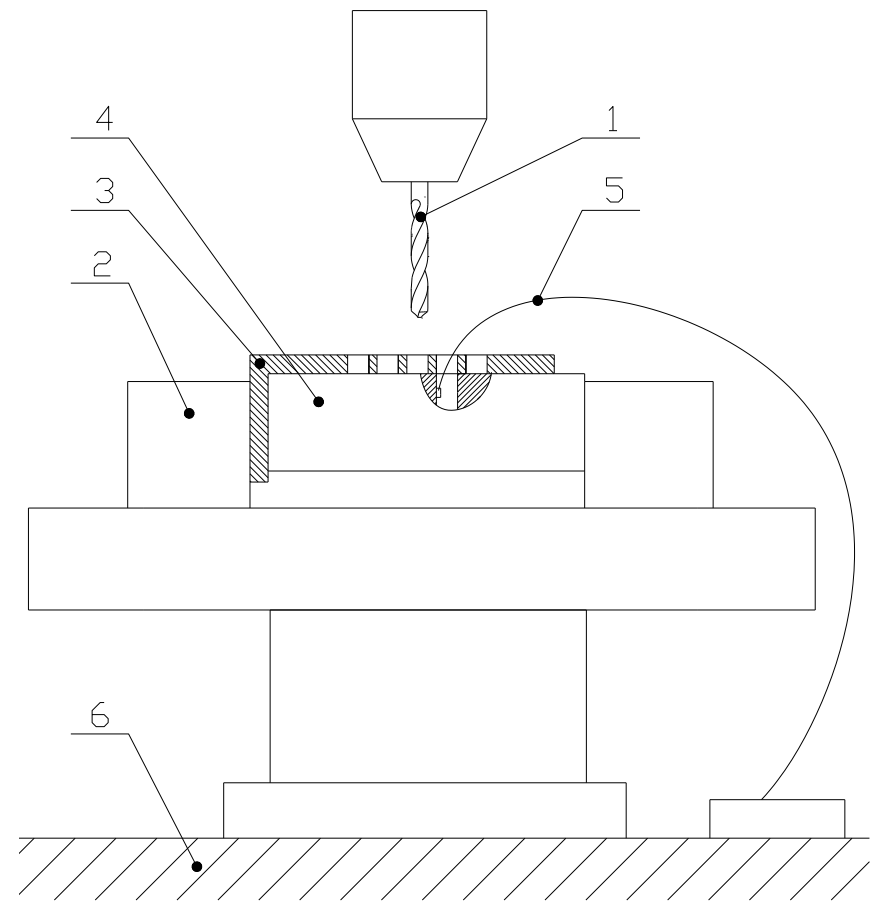

1-drill 2-fixture 3-guiding device 4-Bone specimen 5- thermocouple 6- workbench

Fig. (3). Experimental equipment.

K-P36 numerical control surface grinding machine made by Schleifring Group. Aerial fog of normal saline spray cooling is generated by Bluebe minimal quantity lubrication supply system manufactured by Fuji Company and then sprayed to the drilling zone through nozzle. This system adjusts the high-precision pump through pulser. On this basis, flow of normal saline and compressed air is controlled. Appropriate gas-liquid ratio is selected. High pressure air can atomize normal saline completely and carry the normal saline droplets easily into the drilling zone.

$\mathrm{K}$-thermocouple was used to measure temperature in bone hole. Known as NiCr-NiSi thermocouple, Kthermocouple is composed of two homogeneous conductors with different compositions. Two conductors are connected at one end to form a couple wire. This couple wire is the positive and negative pole of the closed loop circuit. Chemical composition of the positive pole (KP) material is $\mathrm{Ni}: \mathrm{Cr}=92: 12$, while that of the negative pole $(\mathrm{KN})$ material is $\mathrm{Ni}: \mathrm{Si}=99: 3$. Temperature range of such $\mathrm{K}$-thermocouple is $200 \sim 1300^{\circ} \mathrm{C}$. Generally, the couple wire ranges from 1.2 4.0 $\mathrm{mm}$ and the insertion depth shall be 8 10 times longer than its protective casing diameter. Manual thermocouple method is to fix the hot ends of two calibrated thermocouples at the 
point where needs to measure temperature and then connect the cold ends to potentiometer or mullivoltmeter in series. Temperature at the testing point could be gained according to meter reading and the thermocouple calibration curve.

The temperature measuring apparatus used in the experiment is shown in Fig. (4). Fig. (4a) is a temperature measuring setup and Fig. (4b) shows connections of the apparatus. It can be seen from Fig. (4a) that the whole temperature measuring equipments includes a $24 \mathrm{~V}$ stabilized voltage supply, a CR800 data acquisition unit, a Kthermocouple and a computer. According to Fig. (4b), the 24 $\mathrm{V}$ stabilized voltage supply provides voltage to the CR800 data acquisition unit. The positive and negative poles of $\mathrm{K}$ thermocouple are connected to the CR800 data acquisition unit which is connected to the computer. In this way, thermoelectromotive forces produced by hot and cold ends of the thermocouple could be collected and recognized by CR800 data acquisition unit. Then, they will be converted into temperature value and stored in the computer. With the real-time clocking of temperature compensation, the CR800 data acquisition unit could calibrate both with the background time and temperature changed system, which are foundations of accurate measurement. Besides, the used Kthermocouple is a standard one with determined specific resistance variation curve against time. It doesn't need calibration before temperature measurement in the experiment.

The experiments consists of four drills: common twist drill, diamond punching pin, diamond bullet-like grinding head and diamond spherical grinding head (Fig. 5a-d).

To increase experimental comparability, each drill has different sizes. Diameter of working part, drill stock diameter and diamond particle size of different drills are listed in Table 2. Apex angle and helix angle of all common twist drills are $118^{\circ}$ and $30^{\circ}$. Working parts of diamond punching pin, diamond bullet-like grinding head and diamond spherical grinding head are cylinder, like bullet and spherical, respectively. All of them are made by electroplating diamond method. Diamond abrasive particles are in irregular arrangement.

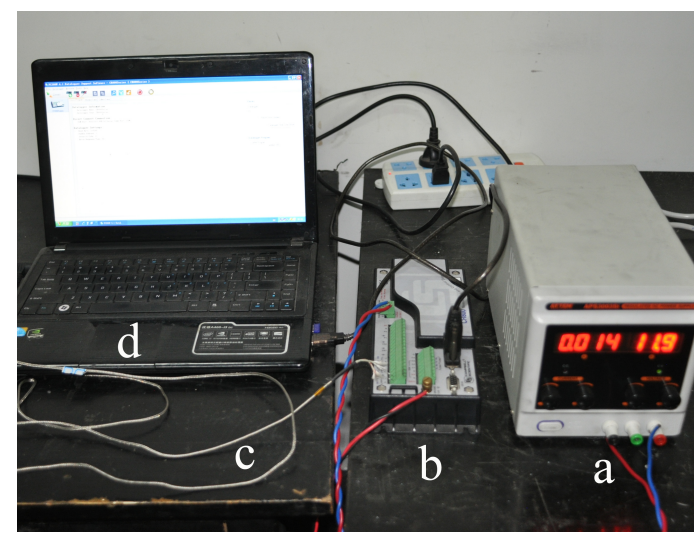

(a)

\subsection{Experimental Materials}

Testing materials mainly include fresh ox bone (Fig. 6) and normal saline cooling liquid. Ox bone is thighbone of adult cattle. This is because abundant researches confirmed that ox bone has the most similar mechanical properties and thermal properties with human bone. However, ox bone has higher density and thicker than human bone. Under same drilling conditions, drilling temperature of ox bone is higher than that of human bone. Hence, it could meet clinical surgical requirements if necrocytosis of ox bone could be avoided. Thighbone has a cylinder hollow structure and is characteristied of even thickness, compact texture and slight mechanical property changes. It is the first choice of testing bone sample. Thickness of the used bone samples ranges between $6 \sim 9 \mathrm{~mm}$. For convenient clamping, ox thighbone was cut into about $5 \mathrm{~cm}$ cylinders before the experiment.

To maintain thermal properties of bone sample, it often takes some measures to protect bone cell activity. Fresh bone samples used in this experiment were immersed in $0.9 \%$ saline solution in first $12 \mathrm{~h}$. Then, they were sealed up in a waterproof plastic bag and stored in a refrigerator. Before the experiment, frozen bone samples were unfrozen in roomtemperature saline solution and then were peeled off from the surface of soft tissues.

Normal saline refers to sodium chloride solution with equal osmotic pressure to animal or human plasma. It is widely used for physiology and clinical purposes. Its concentration is $0.85 \sim 0.9 \%$ for mammals and human bodies. The main medical function of normal saline is to maintain equal pressure of inner and outer cells to prevent water loss. This experiment used $0.9 \%$ sodium chloride injection as spray cooling medium. Firstly, bone cell activity shall be maintained to the maximum extent in clinical surgery. On the other hand, normal saline has high heat exchange coefficient and can rise of drilling temperature effectively.

\subsection{Experimental Condition}

Since it is difficult to measure temperature inside the bone hole, this experiment used K-thermocouple to measure temperature at $0.5 \mathrm{~mm}$ deep, of the hole wall (Fig. 7). Fig. (7a)

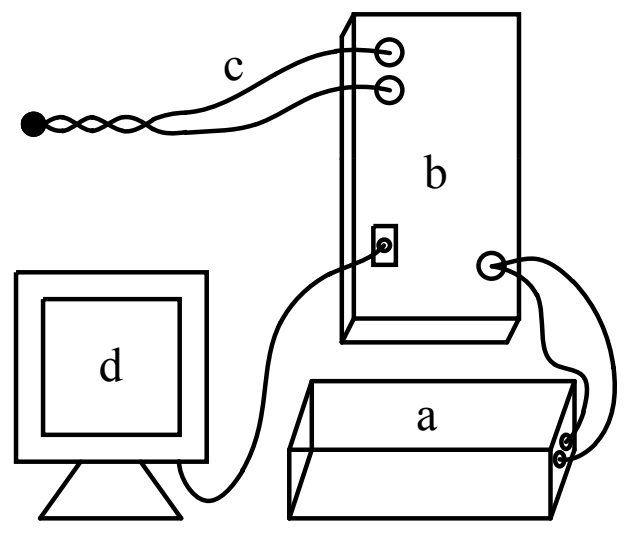

(b)

a-stabilized voltage supply b-CR800 data acquisition unit c- K-thermocouple d- computer

Fig. (4). The temperature measuring apparatus. 


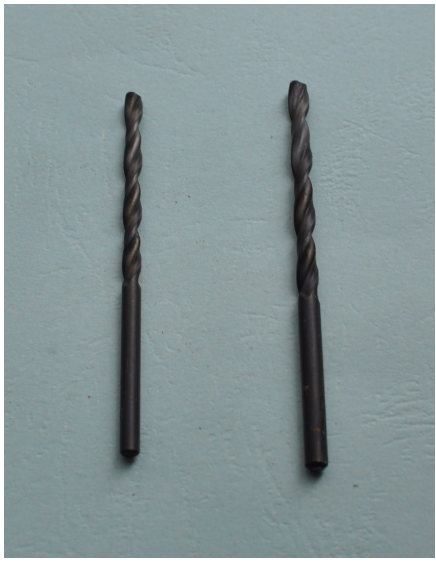

(a)

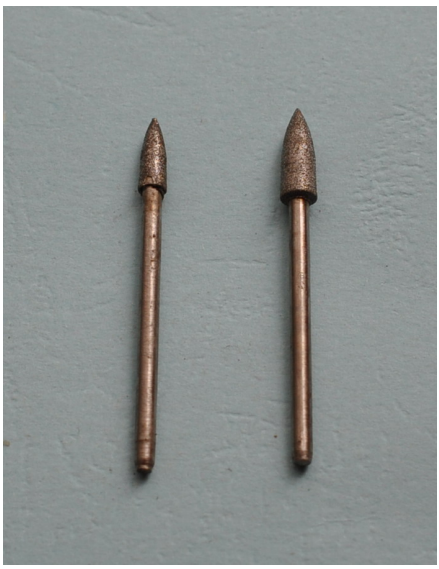

(c)

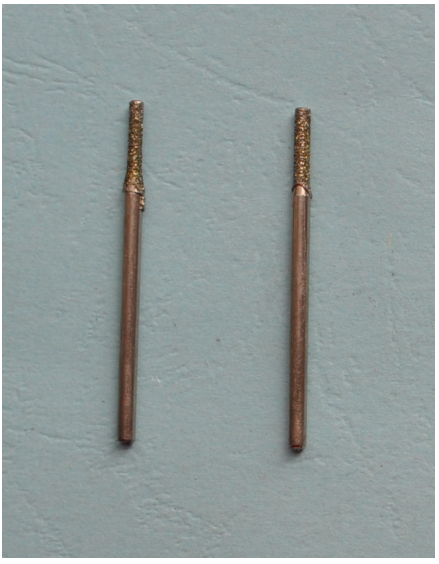

(b)

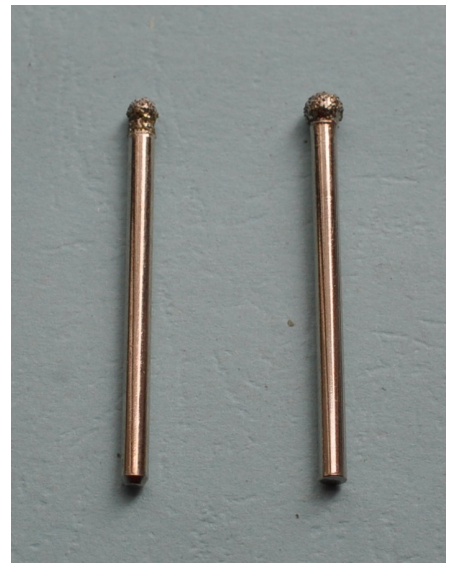

(d)

Fig. (5). The pictures of different drills.

Table 2. The size of different drills.

\begin{tabular}{|c|c|c|c|}
\hline Drills & Diameter of Working Part (mm) & Drill Stock Diameter (mm) & Diamond Particle Size Number \\
\hline common twist drill & $\begin{array}{l}3.0 \\
4.0\end{array}$ & $\begin{array}{l}3.0 \\
4.0\end{array}$ & - \\
\hline diamond punching pin & $\begin{array}{l}2.5 \\
3.0\end{array}$ & 2.35 & $45 \#$ \\
\hline diamond bullet-like grinding head & $\begin{array}{l}3.0 \\
4.0\end{array}$ & 2.35 & $45 \#$ \\
\hline diamond spherical grinding head & $\begin{array}{l}3.0 \\
4.0\end{array}$ & 2.35 & $45 \#$ \\
\hline
\end{tabular}

is an experimental installation of temperature measurement plan. The bone sample was clamped tightly by a jaw vice. A small hole was drilled firstly on one side of the cross section and the hot end of the thermocouple was inserted into this small hole. The hot end was in full contact with the hole bottom. Next, the thermocouple was fixed. Finally, drilling experiment was implemented at the place of $0.5 \mathrm{~mm}$ away from the hot end. Fig. (7b) is the sketch map of temperature measurement plan. The small hole for putting the thermocouple is $6.0 \mathrm{~mm}$ away to the external bone surface and the small hole is $1.5 \mathrm{~mm}$ bigger in diameter. Since the wire diameter of the used $\mathrm{K}$-thermocouple is $1.2 \mathrm{~mm}$ and the insertion depth shall be $8 \sim 10$ times longer than its protective casing diameter. The small hole depth for putting the thermocouple was determined $10 \mathrm{~mm}$. The drilling position shall be at the same axis with the small hole and the drilling hole wall shall be of $0.5 \mathrm{~mm}$, far away from the thermocouple. Therefore, measured temperature in the experiment is temperature at the place of $0.5 \mathrm{~mm}$ away from the drilling wall and $6 \mathrm{~mm}$ away from bone surface.

Single-factor variable method was applied. Drill shape, speed of mainshaft, axial feed speed and cooling mode are main influencing factors. A total of four groups of 
experiments were conducted, recorded as A, B, C and D. Each group only has one variable that changes and other variables that are fixed. Experiment at plans are presented in Table 3.

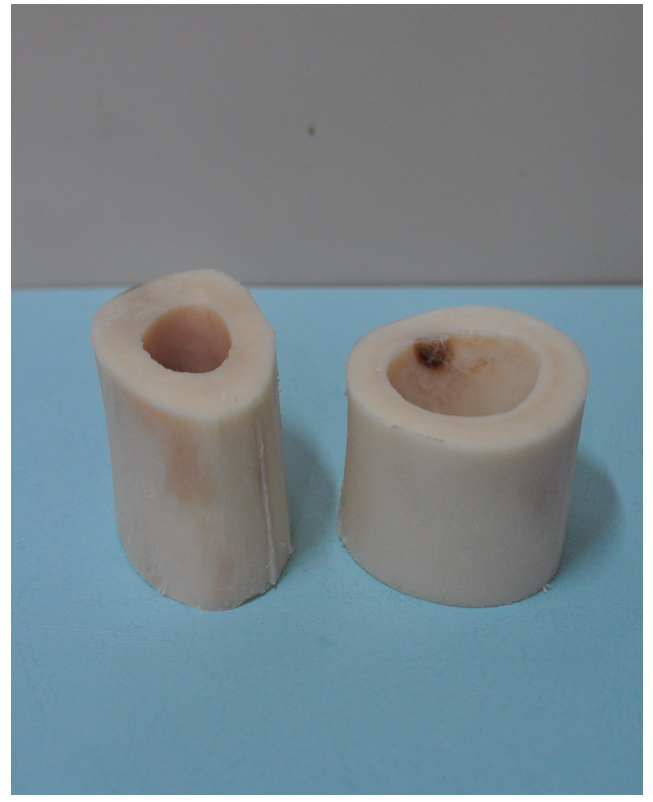

Fig. (6). Bone specimen.

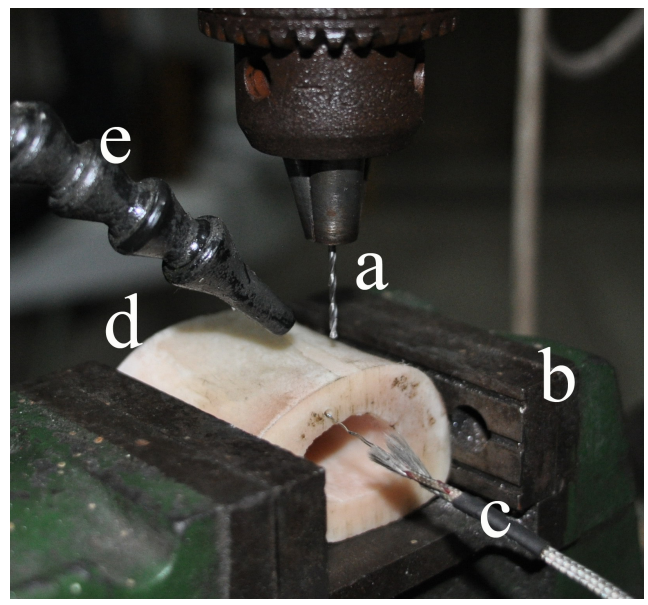

(a)

\section{RESULTS AND DISCUSSION}

\subsection{The Effect Different Drills on Bone Drilling Temperature}

Effect of drill shape on drilling temperature was tested using same bone sample under 2,100 r/min drill speed, $0.5 \mathrm{~mm} / \mathrm{s}$ axial feed speed and air cooling conditions. $4.0 \mathrm{~mm}$ common twist drill, diamond spherical grinding head and diamond bullet-like grinding heads were used. The corresponding time-dependent variation curves of temperature at the point of $6 \mathrm{~mm}$ deep and $0.5 \mathrm{~mm}$ away from the hole wall are shown in Fig. (8).

In Fig. (8), temperature at the measuring point shows an inverse "V-shaped" variation trend no matter what kind of drills is used. The drilling temperature peak is achieved at about $15 \mathrm{~s}$. The maximum drilling temperature of diamond spherical grinding head is $46.31^{\circ} \mathrm{C}$. The maximum drilling temperature of common twist drill is $42.1^{\circ} \mathrm{C}$ and that of diamond bullet-like grinding head is $38.29^{\circ} \mathrm{C}$. This indicates that drilling shape could influence drilling temperature greatly. It is suggested to choose appropriate drill to lower the drilling temperature.

\subsection{The Effect Drill Speed on Bone Drilling Temperature}

Influence law of speed of mainshaft on drilling temperature was analyzed by $4.0 \mathrm{~mm}$ diamond spherical

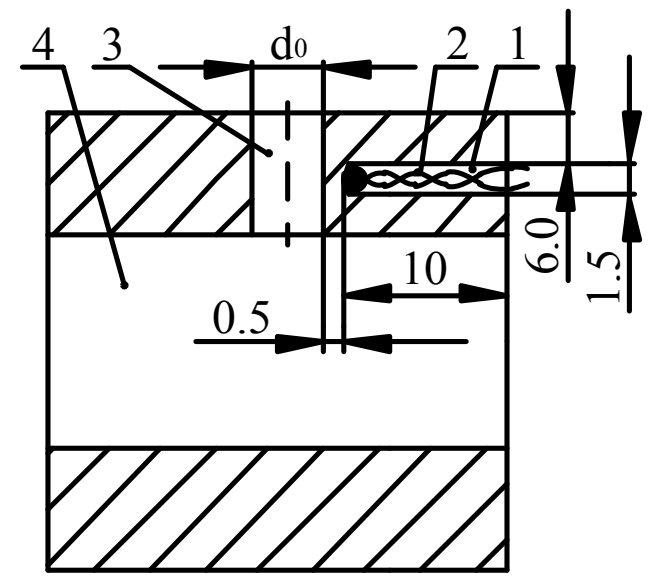

(b)

a-drill b- fixture $\mathbf{c}$ - K-thermocouple $\mathbf{d}$ - Bone sample e- normal saline spray cooling

1- $0.5 \mathrm{~mm}$ diameter small hole 2- K-thermocouple 3- drill 4- marrow cavity

Fig. (7). The experimental installation of temperature measurement.

Table 3. The experimental parameters.

\begin{tabular}{|c|c|c|c|c|c|}
\hline Groups & Drills & Drill Diameter $\mathbf{d}_{\mathbf{0}} / \mathbf{m m}$ & Drill Speed n/(r/min) & Feed Speed $\mathbf{v}_{\mathbf{f}} /(\mathbf{m m} / \mathbf{s})$ & Cooling Modes \\
\hline \hline A & $\begin{array}{c}\text { common twist drill } \\
\text { diamond spherical grinding head } \\
\text { diamond bullet-like grinding head }\end{array}$ & 4.0 & 2100 & 0.5 & air cooling \\
\hline B & diamond spherical grinding head & 4.0 & $\begin{array}{c}560,900, \\
1250,2100\end{array}$ & 0.5 & air cooling \\
\hline C & diamond punching pin & 3.0 & 2100 & $0.5 ; 1.0 ; 1.5 ; 2.0$ & air cooling \\
\hline D & diamond bullet-like grinding head & 3.0 & 2100 & 0.5 & $\begin{array}{c}\text { air cooling pouring cooling } \\
\text { spray cooling }\end{array}$ \\
\hline
\end{tabular}




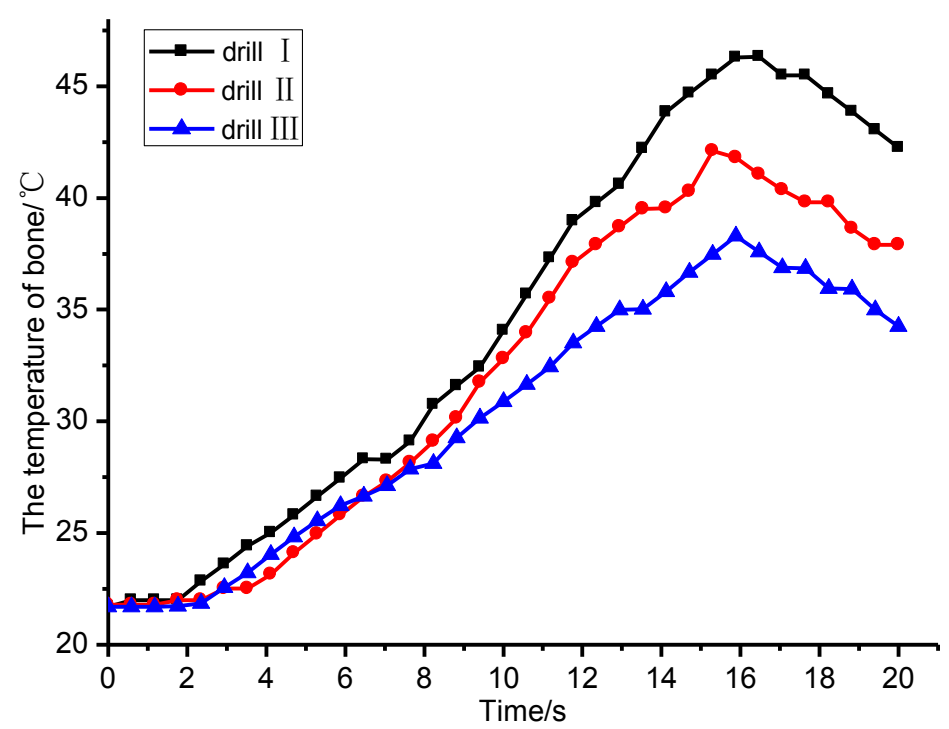

I - diamond spherical grinding head; II - common twist drill; III - diamond bullet-like grinding head drill

Fig. (8). Curve of temperature change in bone versus time with different drills.

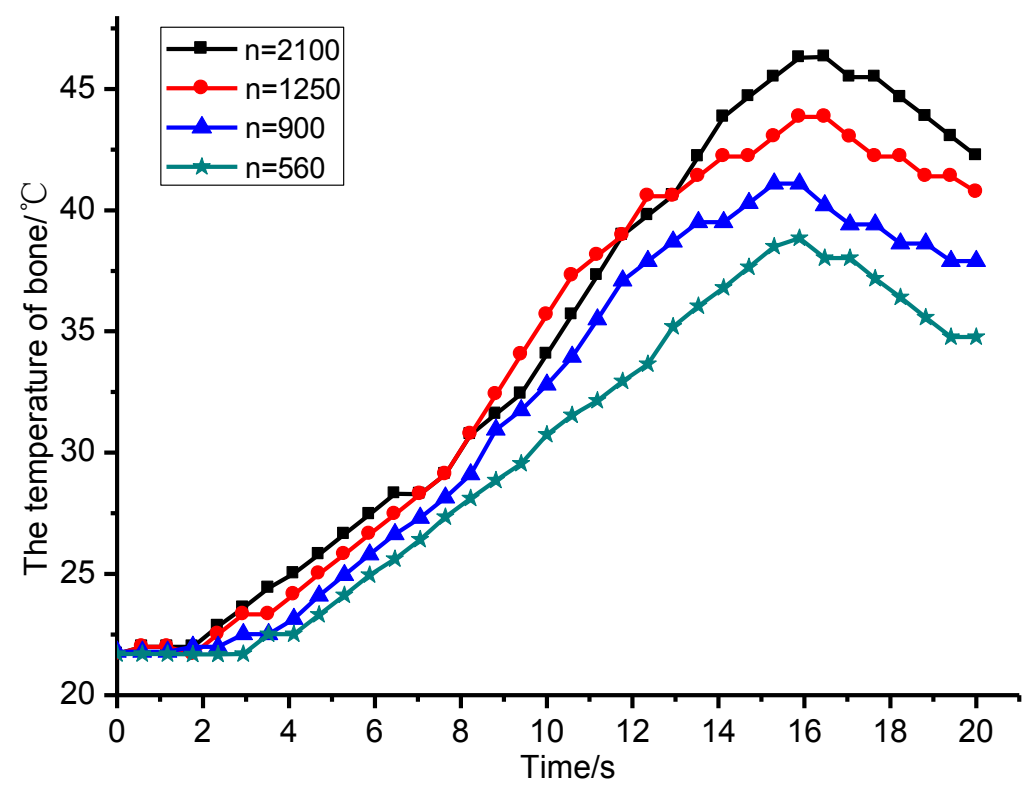

Fig. (9). The experimental curve of temperature change in bone versus time with different revolution.

grinding head under $0.5 \mathrm{~mm} / \mathrm{s}$ feed speed and air cooling conditions. Four speeds of mainshaft were used: $560 \mathrm{r} / \mathrm{min}$, $900 \mathrm{r} / \mathrm{min}, 1,250 \mathrm{r} / \mathrm{min}$ and 2,100 r/min. The corresponding time-dependent variation curves of temperature at the point 6 $\mathrm{mm}$ deep and $0.5 \mathrm{~mm}$ was away from the hole wall which presented in Fig. (9).

It can be seen from Fig. (9) that all four temperature curves show an inverse "V-shaped" variation law as drilling goes on. The maximum drilling temperature of the measuring point is achieved at about $15 \mathrm{~s}$. The drilling temperatures at same time under is $560 \mathrm{r} / \mathrm{min}, 900 \mathrm{r} / \mathrm{min}$, $1,250 \mathrm{r} / \mathrm{min}$ and $2,100 \mathrm{r} / \mathrm{min}$ are $38.84^{\circ} \mathrm{C}, 41.1^{\circ} \mathrm{C}, 43.84^{\circ} \mathrm{C}$ and $46.31^{\circ} \mathrm{C}$. This reflects that under same of other drilling parameters, drilling temperature increases with the increase of speed of mainshaft.

\subsection{The Effect Feed Speed on Bone Drilling Temperature}

Influence law of feed speed on drilling temperature was discussed by $3.0 \mathrm{~mm}$ diamond punch pin under 2,100 r/min speed of mainshaft and air cooling conditions. Four feed speeds $(0.5 \mathrm{~mm} / \mathrm{s}, 1.0 \mathrm{~mm} / \mathrm{s}, 1.5 \mathrm{~mm} / \mathrm{s}$ and $2.0 \mathrm{~mm} / \mathrm{s})$ were analyzed. The corresponding time-dependent variation curves of temperature at the point $6 \mathrm{~mm}$ of deep and was 0.5 $\mathrm{mm}$ away from the hole wall are presented in Fig. (10).

In Fig. (10), all temperature variation curves under different feed speeds increase firstly and then decrease. The maximum drilling temperatures at the same time under 0.5 $\mathrm{mm} / \mathrm{s}, 1.0 \mathrm{~mm} / \mathrm{s}, 1.5 \mathrm{~mm} / \mathrm{s}$ and $2.0 \mathrm{~mm} / \mathrm{s}$ are $39.61^{\circ} \mathrm{C}$, $38.64^{\circ} \mathrm{C}, 38.19^{\circ} \mathrm{C}$ and $35.34^{\circ} \mathrm{C}$, respectively. This shows an inversely proportional relationship between drilling temperature and feed speed. 


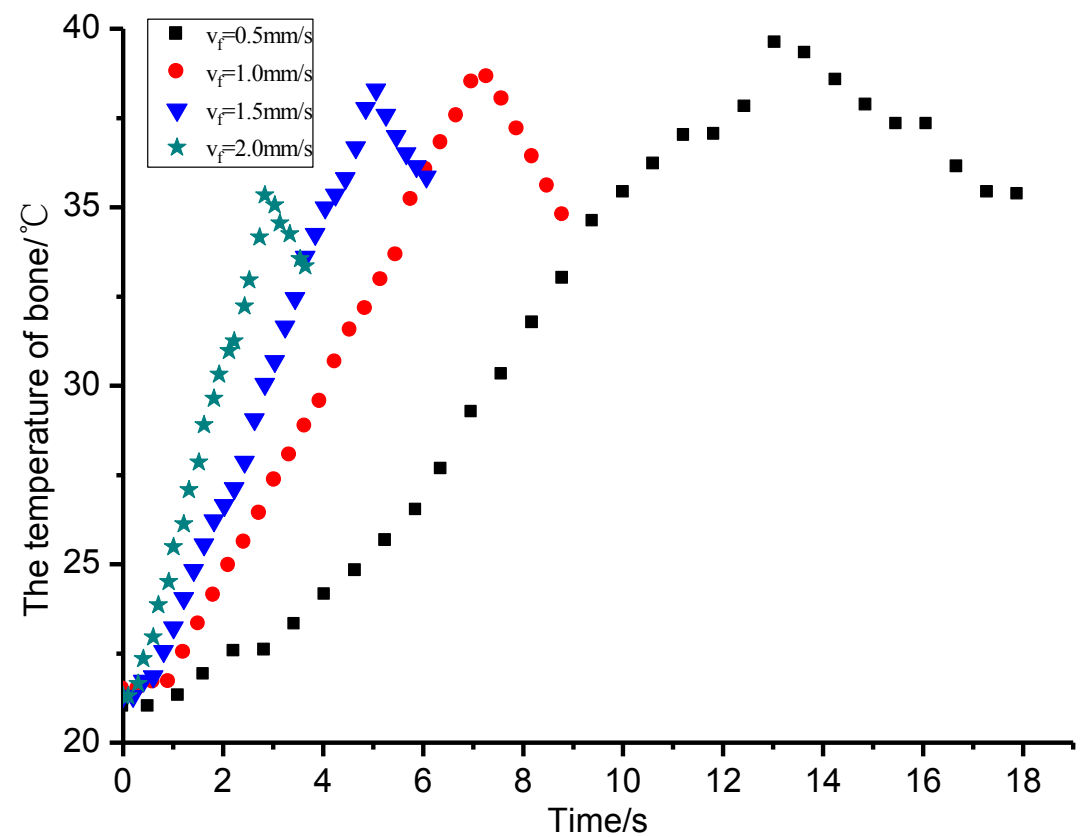

Fig. (10). The experimental curve of temperature change in bone versus time with different feed speeds.

\subsection{The Effect Cooling Modes on Bone Drilling Temperature}

Effect of cooling modes on drilling temperature was studied by $3.0 \mathrm{~mm}$ diamond bullet-like grinding head under $2,100 \mathrm{r} / \mathrm{min}$ speed of mainshaft and $0.5 \mathrm{~mm} / \mathrm{s}$ feed speed. Natural air cooling, normal saline pouring cooling and normal saline spray cooling are involved in the experiment. The flow rate of normal saline pouring cooling was $20 \mathrm{~L} / \mathrm{min}$ and the flow rate of normal saline spray cooling was $40 \mathrm{ml} / \mathrm{h}$. The delivery pressure of cooling medium was 5 bar 6 bar.

The time-dependent variation curves of temperature at the point $6 \mathrm{~mm}$ deep and $0.5 \mathrm{~mm}$ away to the hole wall under different cooling modes are shown in Fig. (11).

Under same cutting parameters, drilling temperatures using different cooling modes all increase firstly and then decrease. The maximum drilling temperature is achieved at about $14 \mathrm{~s}$. Test results showed that normal saline spray cooling has the lowest maximum drilling temperature of $\left(29.34^{\circ} \mathrm{C}\right)$ at same depth, following by normal saline pouring cooling of $\left(32.45^{\circ} \mathrm{C}\right)$ and air cooling of $\left(40.28^{\circ} \mathrm{C}\right)$ successively. This symbolizes that cooling mode could affect drilling temperature significantly. Normal saline spray cooling has the best cooling effect, while air cooling is the poorest.

\section{CONCLUSION}

The drill shape can influence drilling temperature greatly. The maximum drilling temperature of diamond spherical grinding head is $46.31^{\circ} \mathrm{C}$. The maximum drilling temperature of common twist drill is $42.1^{\circ} \mathrm{C}$ and that of

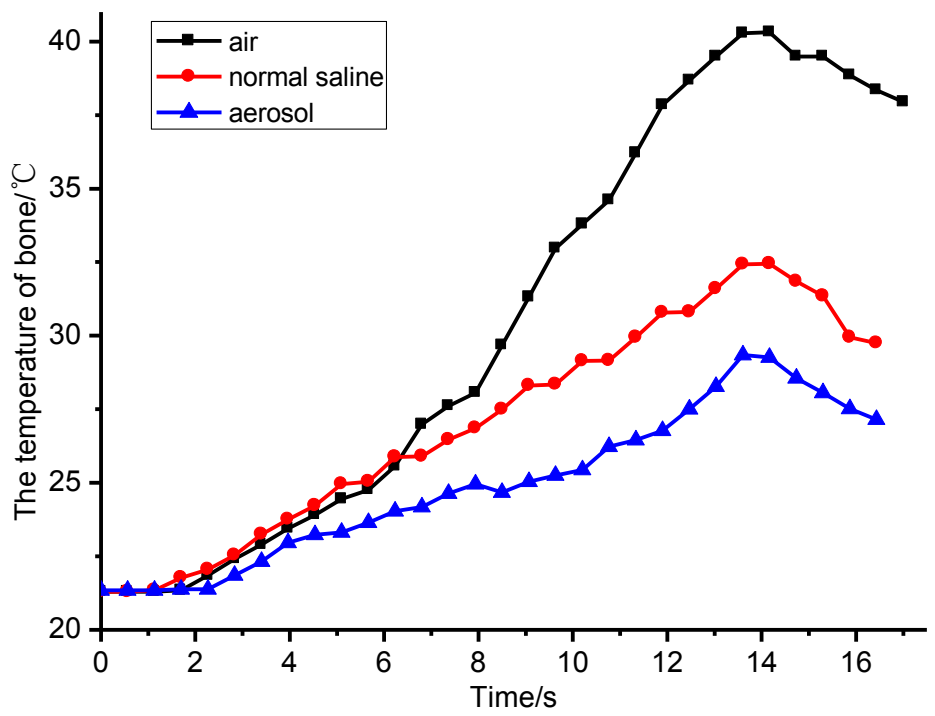

Fig. (11). The experimental curve of temperature change in bone versus time with different cooling ways. 
diamond bullet-like grinding head is $38.29^{\circ} \mathrm{C}$. It is suggested to choose appropriate drill to lower the drilling temperature.

The drilling temperatures at drill speed under $560 \mathrm{r} / \mathrm{min}$, $900 \mathrm{r} / \mathrm{min}, 1,250 \mathrm{r} / \mathrm{min}$ and $2,100 \mathrm{r} / \mathrm{min}$ are $38.84^{\circ} \mathrm{C}, 41.1^{\circ} \mathrm{C}$, $43.84^{\circ} \mathrm{C}$ and $46.31^{\circ} \mathrm{C}$. This reflects that under same of other drilling parameters, drilling temperature increases with the increase of drill speed.

The maximum bone drilling temperatures of diamond punch pin is under $2,100 \mathrm{r} / \mathrm{min}$ speed of mainshaft and air cooling conditions vary as feed speed increase firstly and then decrease.

The normal saline spray cooling has the lowest maximum drilling temperature of $\left(29.34^{\circ} \mathrm{C}\right)$ at same depth, following by normal saline pouring cooling of $\left(32.45^{\circ} \mathrm{C}\right)$ and air cooling of $\left(40.28^{\circ} \mathrm{C}\right)$ successively. The normal saline spray cooling has the best cooling effect, followed by normal saline pouring cooling and air cooling successively.

\section{CONFLICT OF INTEREST}

The authors confirm that this article content has no conflict of interest.

\section{ACKNOWLEDGEMENTS}

This research was financially supported by the National Natural Science Foundation of China (51175276), Qingdao Science and Technology Program of Basic Research Projects (14-2-4-18-jch), and Huangdao District Application Science and Technology Project (2014-1-55).

\section{REFERENCES}

[1] Peng C, Xiao T, Liang YQ. The changes of the methods and principles of the bone fracture treatments, J Med Philos 2005; 26(7): 17-9.

[2] Qi GX, Dai KR. Operative techniques in orthopaedic surgery. Am J Chin Med 2007; 17(12): 1283-4.

[3] Huiskes WJ. Some fundamental aspects of human joint replacement, analyses of stresses and heat conduction in boneprosthesis structures. Acta Orthop Scand Suppl 1980; 185: 208-1.

[4] Mullaji AB, Thomas TL. Low-energy subtrochanteric fractures in elderly patients: results of fixation with the sliding screw plate. J Trauma 1993; 34(1): 56-61.

[5] Wachtl SW, Gautier E, Jakob RP. Low reoperation rate with the Medoff sliding plate: 1 technical failure in 63 trochanteric hip fractures. Acta Orthop Scand 2001; 72(2): 141-5.

[6] Eriksson RA, Albrektsson T, Magnusson B. Assessment of bone viability after heat trauma: a histological, histochemical and vital microscopic study in the rabbit. Scand J Plast Reconstr Surg Hand Surg 1984; 18(3): 261-8.

[7] Guo BF. Orthopaedic Surgery. Scientific and Technological Documents Publishing House 2004.

[8] Augustin G, Davila S, Mihoci K, Udiljak T, Vedrina DS, Antabak A. Thermal osteonecrosis and bone drilling parameters revisited. Arch Orthop Trauma Surg 2008; 128(1): 71-7.

[9] Davidson RH, James DF. Drilling in bone: modeling heat generation and temperature distribution. J Biomech Eng-T Asme 2003; 125(3): 305-14.

[10] Yang YX, Wang CY, Qin Z, Xu LL, Song YX, Chen HY. Drilling force and temperature of bone by surgical drill. Adv Mat Res 2010; 126-128: 779-84.

[11] Udiljak T, Ciglar D, Skoric S. Investigation into bone drilling and thermal bone necrosis. APEM 2007; 2(3): 103-12.

[12] Matthews LS, Hirsch C. Temperatures measured in human cortical bone when drilling. J Bone Joint Surg Am 1972; 54(2): 297-308.
[13] Vaughn RC, Peyton FA. The influence of rotational speed on temperature rise during cavity preparation. J Dent Res 2001; 30(5): 737-4.

[14] Cameron JR, Sorenson J. Measurement of bone mineral in vivo: an improved method. Science 2000; 142(3589): 230-2.

[15] Sun JJ, Geng J. The mechanical properties of human cortical bone. Adv Mech 1987; 17(2): 200-15.

[16] Karmani S. The thermal properties of bone and the effects of surgical intervention. Curr Orthop 2006; 20(1): 52-8.

[17] Hillery MT, Shuaib I. Temperature effects in the drilling of human and bovine bone. J Mat Process Technol 1999, 92(93): 302-8.

[18] Knudson, Duane. Fundamentals of biomechanics. Springer: USa 2007.

[19] Yang YX. Study on drilling performance of new surgical drill. Guangdong University of Technology 2010.

[20] Ma H-L, Li C-H. The axial force controllable surgical bone drill using abrasive drill. China Patent 201320016746.2, July 31, 2013.

[21] Ma H-L, Li C-H. The axial force controllable surgical bone drill using brazed twist drill. China Patent 201320015561.X, July 31, 2013.

[22] Ma H-L, Li C-H. The axial force controllable surgical bone drill using step drill. China Patent 201320020970.9, July 31, 2013.

[23] Ma H-L, Li C-H. The axial force controllable surgical bone drill using brazed PCBN superhard material drill. China Patent 201320016750.9 , July $31,2013$.

[24] Augustin G, Zigman T, Davila S, Udilljak T, Staroveski T, Brezak $\mathrm{D}$, Babic S. Cortical bone drilling and thermal osteonecrosis. Clin Biomech 2012; 27(4): 313-25.

[25] Davidson RH, James DF. Measurement of thermal conductivity of bovine cortical bone. Med Eng Phys 2000; 22(10): 741-7.

[26] Karmani S. The thermal properties of bone and the effects of surgical intervention. Curr Orthop 2006; 20(1): 52-8.

[27] Sener BC, Dergin G, Gursoy B, Kelesoglu E, Slih I. Effects of irrigation temperature on heat control in vitro at different drilling depths. Clin Oral Implants Res 2009; 20(3): 294-8.

[28] Augustin G, Davila S, Udiljak T, Vedrina DS, Bagatin D. Determination of spatial distribution of increase in bone temperature during drilling by infrared thermography: preliminary report. Arch Orthop Trauma Surg 2009; 129(5): 703-9.

[29] Lee JE, Ozdoganlar OB, Rabin Y. An experimental investigation on thermal exposure during bone drilling. Med Eng Phys 2012; 34(10): 1510-20.

[30] Lee JE, Gozen BA, Ozdoganlar OB. Modeling and experimentation of bone drilling forces. J Biomech 2012; 45(6): 1076-83.

[31] Alam K, Mitrofanov AV, Silberschmidt VV. Experimental investigations of forces and torque in conventional and ultrasonically-assisted drilling of cortical bone. Med Eng Phys 2011; 33(2): 234-9.

[32] Pandey RK, Panda SS. Drilling of bone: a comprehensive review. J Orthop Traumatol 2013; 4(1): 15-30.

[33] Oliveira N, Alaejos AF, Mareque BJ, Ferrés PE, Hernández AF. Thermal changes and drill wear in bovine bone during implant site preparation. A comparative in vitro study: twisted stainless steel and ceramic drills. Clin Oral Implants Res 2012; 23(8): 963-9.

[34] Leeson MC, Lippitt SB. Thermal aspects of the use of polymethyl methacrylate in large metaphyseal defects in bone: a clinical review and laboratory study. Clin Orthop Relat Res 1993; 295: 239-45.

[35] Sumer M, Misir AF, Telcioglu NT, Guler AU, Yenisey M. Comparison of heat generation during implant drilling using stainless steel and ceramic drills. Int J Oral Maxillofac Surg, 2011, 69(5): 1350-4.

[36] Marković A, Mišić T, Miličić B, Guirado LC, Aleksić Z, Đinić A. Heat generation during implant placement in low-density bone: effect of surgical technique, insertion torque and implant macro design. Clin Oral Implants Res 2013; 24(7): 798-805.

[37] Bertollo N, Milne RM, Ellis LP, Stephens PC, Gillies RM, Walsh R. A comparison of the thermal properties of 2-and 3-fluted drills and the effects on bone cell viability and screw pull-out strength in an ovine model. Clin Biomech (Bristol, Avon) 2010; 25(6): 613-7.

[38] Soriano J, Garay A, Aristimuño P, Arrazola PJ. Study and improvement of surgical drill bit geometry for implant site preparation. Biochem Mol Biol Educ 2014; 74(5-8): 615-27.

[39] Harder S, Egert C, Wenz HJ, Jochens A, Kern M. Influence of the drill material and method of cooling on the development of intrabony temperature during preparation of the site of an implant. Br J Oral Maxillofac Surg 2013; 51(1): 74-8. 
[40] Oh HJ, Wikesjö ME, Kang HS, Ku Y, Eom TG, Koo KT. Effect of implant drill characteristics on heat generation in osteotomy sites: a pilot study. Clin Oral Implants Res 2011, 22(7): 722-6.

[41] Sezek S, Aksakal B, Karaca F. Influence of drill parameters on bone temperature and necrosis: a FEM modelling and in vitro experiments. Comput Mater Sci 2012; 60: 13-8.

[42] Heinemann F, Hasan I, Kunert C, et al. Experimental and histological investigations of the bone using two different oscillating osteotomy techniques compared with conventional rotary osteotomy. Ann Anat 2012; 194(2): 165-70

[43] Boner V, Kuhn P, Mendel T, Gisep A. Temperature evaluation during PMMA screw augmentation in osteoporotic bone-an in vitro study about the risk of thermal necrosis in human femoral heads. J Biomed Mater Res Part B Appl. Biomater 2009; 90(2): 842-8.

[44] Nam JS, Lee PH, Lee SW. Experimental characterization of microdrilling process using nanofluid minimum quantity lubrication. Int J Mach Tool Manuf 2011; 51(7): 649-52.

[45] Gok K, Gok A, Kisioglu Y. Optimization of processing parameters of a developed new driller system for orthopedic surgery applications using Taguchi method. Int J Adv Manuf Tech 2014; $76(5-8): 1437-48$

(C) Hou et al.; Licensee Bentham Open.

This is an open access article licensed under the terms of the (https://creativecommons.org/licenses/by/4.0/legalcode), which permits unrestricted, noncommercial use, distribution and reproduction in any medium, provided the work is properly cited. 